International Journal of Biology, Pharmacy and Allied Seiences (IJBPAS)

'A Bridge Betueen Caboratory and QRando'

Www.ibpas.com

\title{
QUANTITATIVE EVALUATION AND CORRELATION OF BASAL REPRODUCTIVE HORMONES PRESENT IN URINE DURING DIFFERENT REPRODUCTIVE PHASES OF FEMALE GOAT: CAPRA HIRCUS
}

\section{JEREMIAH KIRUBANANTH K ${ }^{1^{*}}$, JERALD AJA ${ }^{1}$, ACHIRAMAN $\mathrm{S}^{\mathbf{2}}$, KAMALAKANNAN $S^{2}$ AND JEGADEESAN PNR ${ }^{3}$}

1: PG and Research Department of Zoology, Jamal Mohammed College, Tiruchirappalli. 2: PG and Research Department of Environmental Biotechnology, Bharathidasan University, Palgalaiperur, Tiruchirappalli

3: Veterinary University Training and Research Centre, Tiruchirapalli - 620023

*Corresponding Author: Jeremiah Kirubananth K: E-Mail: jeremiah.zy@bhc.edu.in

Received $5^{\text {th }}$ Feb. 2020; Revised $2^{\text {nd }}$ March 2020; Accepted $5^{\text {th }}$ April 2020; Available online $1^{\text {st }}$ Oct. 2020

\section{ABSTRACT}

The proteinaceous chemical substance produced by specialized endocrine glands located in different parts of body and by neurons called neurosecretory cells. The production and secretion of hormones according to the need of the physiological function also acts as a behaviour regulating mechanism in both invertebrates and vertebrates' Hormonal influences on behaviour can be roughly divided in two categories: educational and organizational effects. In educational effects hormones act as triggering influences in organizational effects of hormones are manifested during an organism's development. Techniques to Explore the Interrelationship between hormones and behavior investigations have used several techniques to explore the interrelationship between hormones and behavior. These include Extirpation or removal, of a particular endocrine gland to assess the absence of a specific hormone on behavior. Six Goats (F-046, F-048, F-049, F-050, F- 051 F-152) mature female goats (4-7 years old) weighing an average of $58.7 \mathrm{Kg}$ were individually penned in open side structures. They were fed with fodder and a concentrate ration once a day and water were available ad libitum. Bioassays to indirectly assess circulating hormones levels by measuring a secondary characteristic such as a skin gland that is dependent on a particular hormone. Radioimmunoassay to directly measure circulating levels of a hormone though the use of 
immunological methods Autoradiography to localize the sites at which hormone uptake occurs. The present findings showed that the adult intact females are having significant amount of all the reproductive hormones in urine at the various reproductive phases of the entire cycle this research hypothesized that the hormones are secreted at the highest level when they receive the mating cue from the opposite sex until, the hormone secretion level is to maintain and fulfill the normal physiological functions. In this study, peak frequencies of both LH and Testosterone were high during ovulating females, low in proestrus phase of females it may increase at the time of arousal thereafter. The peak magnitude of LH showed a progressive decrease in female. The peak magnitude of Testosterone, however, increased after 18 weeks of age. This appears to trigger the increased Testosterone concentration which is necessary to suppress the LH secretion after sexual maturity.

\section{Keywords: Reproductive phase, Estrus, hormones, Radioimmunoassay}

\section{INTRODUCTION}

Hormones are proteinaceous chemical substance produced either by specialized endocrine glands located in various parts of body or by neurons called neurosecretory cells. Here, we will consider how the endocrine system acts as a behavior regulating mechanism in both invertebrates and vertebrates through the production of hormones Before going deep in the details, we should have a clear concept that both the nervous and endocrine system are feedback systems that form key points of the body's mechanism Both invertebrates and invertebrates these two systems show a dual system of interrelationship, i.e., glands are interconnected through the circulatory system or they are closely tied to the nervous system through names connecting with brain. Hormonal influences on behavior can be roughly divided in two categories: educational and organizational effects. In educational effects hormones act as triggering influences in organizational effects of hormones are manifested during an organism's development. The following classification will give a clear understanding of different types of effects (in behavioral aspects). Techniques to Explore the Interrelationship Between Hormones and Behavior Investigations have used several techniques to explore the interrelationship between hormones and behavior. These include Extirpation or removal, of a particular endocrine gland to assess the absence of a specific hormone on behavior. Hormone replace replacement therapy injection of specific hormones or transplantation of a gland. Blood transfusion to transfer the "hormonal state" of one animal to another in order to observe the behavioral effect. Bioassays to indirectly assess circulating hormones 
levels by measuring a secondary characteristic such as a skin gland, that is dependent on a particular hormone. Radioimmunoassay to directly measure circulating levels of a hormone though the use of immunological methods Autoradiography to localize the sites at which hormone uptake occurs. The process whereby the adult form of an insect emerges from the pupa after metamorphosis is called eclosion and is an activation effect controlled hormonally. The eclosion hormone which is produced by neurosecretory cells in the brain plays a critical role in this Example. If the eclosion hormone is crificted into pupae that are near the end of the metamorphosis eclosion behavior, such as abdomen movements and being spreading after emergence can be activated at any time of the deny. Moths that have their brains removed usually emerge; therefore, the presence of eclosion hormone is not an absolute requirement for eclosion to take place. The process, however, is not as coordinated in brainless subjects and some activities (e.g),, wing spreading are usually absent. Thus, though the hormone may not be necessary for eclosion, it does appear to be necessary for proper coordination of the sequence. In adult male desert locust's sexual behavior is exhibited when corpora allata are removed and when corpora allata is transplanted from other locust is restores its sexual behavior however similar experiments have revealed that corpora allata are not needed for sexual behavior in certain grasshoppers.

The organizational effects of hormones on female behavior have been conducted on guinea pigs and Rhesus monkey. Female progeny of females that were treated with androgens when they were masculinized and they exhibited male like sexual behavior. Some activation effects involve complex interactions among behaviours, hormones and specific environmental estimate. Will discuss in detail one example reproductive sequences in ring doves which illustrates this interrelationships. To understand the action of a hormone, both the stimulation and its release and its effects upon behavior must be known. The mechanisms by which hormones affect behavior, is also complex. separates four theoretical possibilities. Hormones may influence behavior through their effects upon. The whole organism (e.g., general activity level) Morphologic structures employed in specific response patterns. Peripheral receptor mechanisms. Integrative functions of the C.N.S. Control of this development of nervous organization. Control of periodic growth and regression of nervous elements. Control of sensitivity of stimulation.

If baby which is injected with testosterone, complete mating responses including 
covering, treating have been observed.

There are many examples which ultimately conclude that some interaction of hormonal action and behavioural development establishes a behavioural organization which then persists in the absence of hormonal influences. Since 1950 research has centered increasingly upon the problem of untangling the delicate and complex interrelationship between hormone the nervous system and behavior.

First prolactin alone does not elicit parental behavior, but requires estrogenic priming. Second, low or hormone can act directly on a peripheral structure involved in behavior. Without involving vagus effects on the C.N.S. Third, The young birds provide the tactile stimuli that elicit regurgitation from the crop. Active research continues to the field of migration too. The small ruminants such as the goat and sheep are economically important farm animals worldwide for their milk, meat, and wool. The response of the female goat to the male is weak but can be induced by the introduction of teaser bucks that had previously been exposed to long days [1, 2]. The odor of the male and its sexual behavior plays a primary role in inducing ovulation, while vocalizations appear to facilitate the display of the does' estrus [1]. Additionally, the sebaceous gland has been indicated as sources of primer pheromone production in goats $[3,4]$. The primer pheromones produced by the male have been known to stimulate the reproductive neuroendocrine system of anestrus animals $[5,6]$. Exposure of a male into a group of anestrus females leads to the activation of sexual activity by influencing the LH secretion and synchronization of ovulation in the sheep and goat $[7,8]$. Just as the influence of primer pheromones in the acceleration of puberty in rodents is well established, the chemosignals from the ram and buck have been found to accelerate puberty in the sheep and goat $[9,10]$. The evidence indicates that 4-ethyl octanoic acid (4EOA) identified in major fleece does not evoke an $\mathrm{LH}$ response in a female conspecific but its derivatives might have pheromonal activity [11]. It was also found that the synthetic 4EOA possessed a releaser pheromone activity that induced specific behavior in the recipient, and female goats showed some interest in the odor $[11,12]$.

The pheromones secreted through the ewe's wool and wax [13] and vaginal secretions [14] sexually attract the ram; however, the nature of the pheromonal compound present in the female is not yet investigated. The volatile substance(s) responsible for female $\mathrm{LH}$ secretion has been found in male sheep hair, skin, and their extracts obtained by organic solvents [15]. It is further reported that the compounds 1, 2-hexadecanediol and 1,2- 
octadecanediol appear to be responsible for this pheromonal effect in sheep. The synthetic compounds are reported to be effective in stimulating $\mathrm{LH}$ release in anestrus ewes. In the domestic sheep, primer pheromones are considered the most important signals involved in sociosexual stimulation of the reproductive processes and male-female interactions induce changes in the pulsatile rhythm of the LH secretion in both sexes, which influences reproductive endocrinology. The occurrence of olfactory memory for the formation of mother-young bond between ewes and lambs is another interesting aspect of a milestone in support of the involvement of pheromonal communication. Sheep have been used as the best model to study the mother-young relationship [16, 17, 18]. The strong bond between ewe and lamb formed shortly after parturition particularly within few hours is very crucial and critical for lamb survival $[\mathbf{1 9}, \mathbf{2 0}]$. The onset of maternal responsiveness and the development of mother-young attachment in sheep are under the control of hormonal and sensory stimulation [21, 22, 23]. Offspring recognition through olfaction in most females is generally believed to be based on the offsprings' individual olfactory signature $[\mathbf{2 4}, \mathbf{2 5}]$, which is believed to originate from its body coat [26] from the anal region [27]. It is reported that majority of the odors from the anal region in animals have been associated with pheromones [28]. The first day of life is entirely dependent on the success of the first suckling episodes [29]. If suckling is prevented during the first few hours after birth by covering the ewes udder, the development of a preference for mother is lowered [30], suggesting that sensory outputs from emanating the suckling influence the development of filial attachment.

A world population of more than 590 million goats is kept for the production of meat, mohair fiber, cashmere fiber, and dairy products and for brush control, and work and companionship. In some countries, such as in Brazil, goats have a significant economic role because they can be raised on very small farms in a wide range of environments. Improving genetic quality and performance of these animals is an important issue, and steroid hormone data can be useful in genetic improvement and assisted reproduction programs. In sheep and goats, exposure to mature males induces ovulation in seasonally anestrous females a phenomenon known as the male effect. It is generally thought that a pheromone, the olfactory cue between conspecifics, plays the dominant role in the male effect [31, 32], although other factors such as visual cues and learning also seem to be involved The initial endocrine event occurring upon exposure to the male 
pheromone is the enhancement of the pulsatile luteinizing hormone $(\mathrm{LH})$ release in female animals [33]. Because pulsatile LH secretion is regulated by the gonadotropin-releasing hormone (GnRH) pulse generator in the hypothalamus, this neural substrate is thought to be the central target of the male pheromone. The domestic goat is a seasonal (short-day) breeder in the temperate regions of the world and is becoming increasingly important as a provider of milk, meat and fiber, particularly in areas of sparse vegetation. No comprehensive data are currently available on the concentrations of Estrogen LH, FSH and testosterone during the critical prepubertal period in the female goat. This research is carried out to understand the presence and interplay of these physical factors on the endocrine secretory modification and to quantitatively, evaluate and correlate the basal reproductive hormones present in urine during different reproductive phases of female goat

\section{MATERIALS AND METHODS ANIMALS AND SAMPLING}

The form situated at Pudukkottai with 300 to 350 Thellycherry goat breed animal model was chosen as a sampling station to carry out this research. A veterinarian with ethical clearance has collaborated with research have done the samplings
Six Goats (F-046, F-048, F-049, F-050, F051 F-152) mature female goats (4-7 years old) weighing an average of $58.7 \mathrm{Kg}$ were individually penned in open side structures. They were fed with fodder and a concentrate ration once a day and water were available ad libitum.

\section{SAMPLING}

Sampling commenced at approximately 06:15-8:30 am on an exact reproductive phase for all goats. The hormone assay has been done using chemiluminescence immunoassay method in RCL DIAGNOSTIC LAB

\section{CHEMILUMINESCENCE}

\section{IMMUNOASSAY (CLIA) METHODS}

Immunoassays based on chemiluminescence have substantially greater sensitivity and dynamic range than those based on earliergeneration detection techniques. Efficient light emission with low background is coupled with the high sensitivity and broad range of the photomultiplier detector. For every photon of light striking the surface of the photomultiplier, there is a 106 fold electronic amplification of the signal. Photomultipliers have very low background noise and inherent dynamic ranges of 5 to 6 orders of magnitude [15].

Chemiluminescence enzyme immunoassay (CLEIA), which integrates the advantages of Immunoassay and chemiluminescence determination such as high specificity and throughput, rapidity and convenience in 
operation and relatively simple and inexpensive instrumentation $[\mathbf{1 6}, \mathbf{1 7 ]}$. The chemiluminescence imaging have also been extensively applied for the evaluation of the spatial distribution of a given target molecule, chemical or biochemical process on macro or microsamples associated with traditional methods, immunohistochemistry (IMH), in situ hybridization (ISH), enzyme or chemical reactions are used for the localization of antigens, gene sequences, enzymes or metabolites in cells and tissue sections [2]. Even though a wide range of different bio- and chemiluminescent systems have been applied in conventional chemiluminescence assays, only a small number of luminescent systems proved suitable for imaging applications. The main requirement, which is particularly crucial in imaging microscopy, is the localization of the luminescent signal in close proximity to the site where the luminescent reaction takes place [6]. For example, bio- and chemiluminescence imaging microscopy a target molecule is often detected through its binding to a biospecific probe labeled with an enzyme that catalyzes a chemiluminescent reaction. Accurate localization of the target, down to the micrometer scale, requires that the light emission take place close to enzyme label [17]. IMH is based on the use of highly specific antibodies, able to bind to an endogenous and/or tumoral antigen (usually a protein), which are subsequently detected by means of class-specific antibodies conjugated

Now, the chemiluminescence immunoassay (CLIA) thus combine the specificity and sensitivity of labeled probes evidenced by chemiluminescence and spatial morphological resolution and localization of the signal of the IMH technique [18]. Among assay methods, chemiluminescence detection represents a versatile, ultrasensitive tool with a wide range of applications in biotechnology. It also gives a sensitive, rapid alternative to radioactivity as a detection principle in IA for the determination of molecules (e.g., proteins, hormones, drugs, nucleic acids and environmental pollutants).

Chemiluminescence is now commonly used for immunoassay in the form of a CL label or as a CL detection reaction for an enzyme or a nanoparticle label. In recent years, CLIA has become very popular in clinical chemistry and environmental analysis, due to its high sensitivity, wide dynamic range and complete automation $[\mathbf{1 9}, \mathbf{2 0}]$. With the development and application of recombinant $\mathrm{Ab}(\mathrm{rAb})$ technology, markers and related techniques, solid-phase materials and improvements in automation, integration and miniaturization, CLIA has acquired an entirely new appearance [17]. To enzymes (Figure 1). Reagents required 
for reactions that produce $\mathrm{CL}$ may be coupled to Abs or antigens (Ags) and used as labels for immunoassay. Since the first report on CL labels in 1976, considerable efforts have been devoted to developing practical CL labeling systems because of their low limits of detection (LODs). Luminol, isoluminol and its derivatives, acridinium ester, horseradish peroxidase (HRP) and alkaline phosphatase ALP) have frequently been employed as CL labels in immunoassay for development and application of CLIA methods. Because the CL-detection methods have very low LODs, new CL labels and related substrates, new label technologies have been studied and obtained staggering results $[12,22]$. Scorilas and co-workers (2005)23 synthesized two novel biotinylated acridinium derivatives, 9-(2-biotinyl-oxyethyl)carboxylate-10-methyl-acridinium triflate (BOCMAT) and 9-(2-biotinyl-amidoethyl)carboxylate-10- methyl- acridinium triflate (BACMAT), and described their luminescent properties and immunoassay applications.

\section{STATISTICAL ANALYSES}

To analyze changes in hormone concentrations, the means were computed for LH, FSH, testosterone and estradiol by averaging the data then they were than analyzed using one way ANOVA analysis of variance to detect significance and means compared using SPSS - 16 software tool Basal serum LH concentrations of multiple samples collected were determined by an iterative process in which high values were excluded until the mean plus three standard deviations (s.d.) of the mean were greater than the remaining values.

\section{RESULT}

The quantitative evaluation of hormones in serum and urine is explained and statistically tabulated below in Table 1-4.

\section{FOLLICLE STIMULATING HORMONE}

The level of FSH gradually increasing till the post ovulatory phase and recorded very less in the pro estrus phase (Table 1, Figure 1). Statistically significant variations are noticed but, in the results, slight variation present in the proestrus phase.

\section{LUTEINIZING HORMONE}

The quantity of luteinizing hormone is very high (Table 2, Figure 2) in the ovulatory phase which is very next to the estrus phase of female showing that the level of LH has secreted and facilitated the ovulation and eliminated along with urine during the ovulatory phase Statistically significant variations is noticed.

\section{ESTROGEN}

Estrogen the hormone responsible for female characteristics are recorded here is very trace (Pica gram) yet they are playing a vital role in the reproductive cycle and the reproductive growth in female it is recorded that the gradual increase (Table 3, Figure 3) of this hormone in the phases of the reproductive cycle. 


\section{TESTOSTERONE}

The level testosterone in this present investigation showing significant increase in the prepubertal and the Testosterone level in the grown female goat recorded very low which in the basal reproductive phase the hormones which responsible for maleness recorded very low (Table 4, Figure 4) in the fully matured female goat. The difference between the hormone testosterones level is significant.

The changes in hormone concentrations, the means were computed for LH, FSH, testosterone and estradiol by averaging the data then they were than analyzed and compared using one way ANOVA analysis of variance to detect significance and means (Table 5-9).

The present findings showed that the adult intact females are having significant amount of all the reproductive hormones in urine at the various reproductive phases of the entire cycle this research hypothesized that the hormones are secreted at the highest level when they receive the mating cue from the opposite sex until, the hormone secretion level is to maintain and fulfill the normal physiological functions

Table 1: FSHin the urine sample $\mathrm{mIU} / \mathrm{ml}$

\begin{tabular}{|l|l|l|l|l|l|l|}
\hline Reproductive phase of does & N1 & N2 & N3 & N4 & N5 & N6 \\
\hline pro Estrus & $\mathbf{0 . 0 6}$ & $\mathbf{0 . 0 4}$ & $\mathbf{0 . 0 6}$ & $\mathbf{0 . 0 5}$ & $\mathbf{0 . 0 6}$ & $\mathbf{0 . 0 4}$ \\
\hline Estrus & $\mathbf{0 . 0 8}$ & $\mathbf{0 . 0 8}$ & $\mathbf{0 . 1}$ & $\mathbf{0 . 1 1}$ & $\mathbf{0 . 0 7}$ & $\mathbf{0 . 0 7}$ \\
\hline ovulatory & $\mathbf{0 . 0 4}$ & $\mathbf{0 . 0 5}$ & $\mathbf{0 . 0 3}$ & $\mathbf{0 . 0 4}$ & $\mathbf{0 . 0 4}$ & $\mathbf{0 . 0 6}$ \\
\hline post ovulatory & $\mathbf{0 . 0 3}$ & $\mathbf{0 . 0 1}$ & $\mathbf{0 . 0 1}$ & $\mathbf{0 . 0 2}$ & $\mathbf{0 . 0 3}$ & $\mathbf{0 . 0 3}$ \\
\hline
\end{tabular}

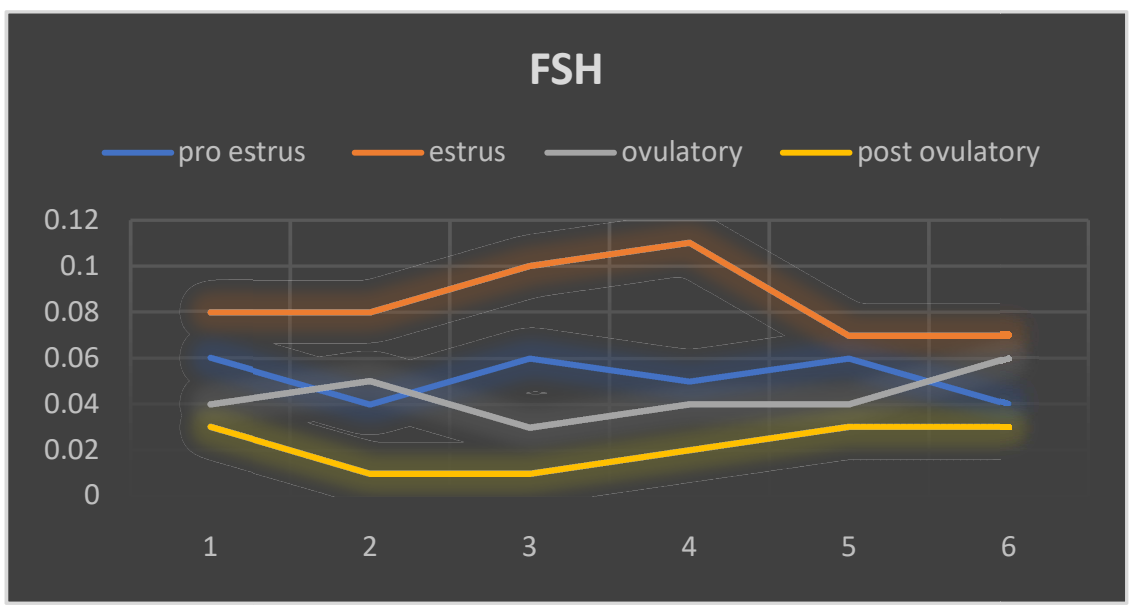

Figure 1: FSHin the urine sample $\mathrm{mIU} / \mathrm{ml}$

Table 2: Luteinizing Hormonein the urine sample $\mathrm{mIU} / \mathrm{ml}$

\begin{tabular}{|c|c|c|c|c|c|c|}
\hline Reproductive phase of does & N1 & N2 & N3 & N4 & N5 & N6 \\
\hline pro estrus & $\mathbf{0 . 0 3}$ & $\mathbf{0 . 0 2}$ & $\mathbf{0 . 0 3}$ & $\mathbf{0 . 0 5}$ & $\mathbf{0 . 0 2}$ & $\mathbf{0 . 0 4}$ \\
\hline estrus & $\mathbf{0 . 0 3}$ & $\mathbf{0 . 0 1}$ & $\mathbf{0 . 0 1}$ & $\mathbf{0 . 0 1}$ & $\mathbf{0 . 0 4}$ & $\mathbf{0 . 0 3}$ \\
\hline ovulatory & $\mathbf{0 . 1}$ & $\mathbf{0 . 1 2}$ & $\mathbf{0 . 1 1}$ & $\mathbf{0 . 0 9}$ & $\mathbf{0 . 0 8}$ & $\mathbf{0 . 1 2}$ \\
\hline post ovulatory & $\mathbf{0 . 0 4}$ & $\mathbf{0 . 0 3}$ & $\mathbf{0 . 0 6}$ & $\mathbf{0 . 0 1}$ & $\mathbf{0 . 0 1}$ & $\mathbf{0 . 0 3}$ \\
\hline
\end{tabular}




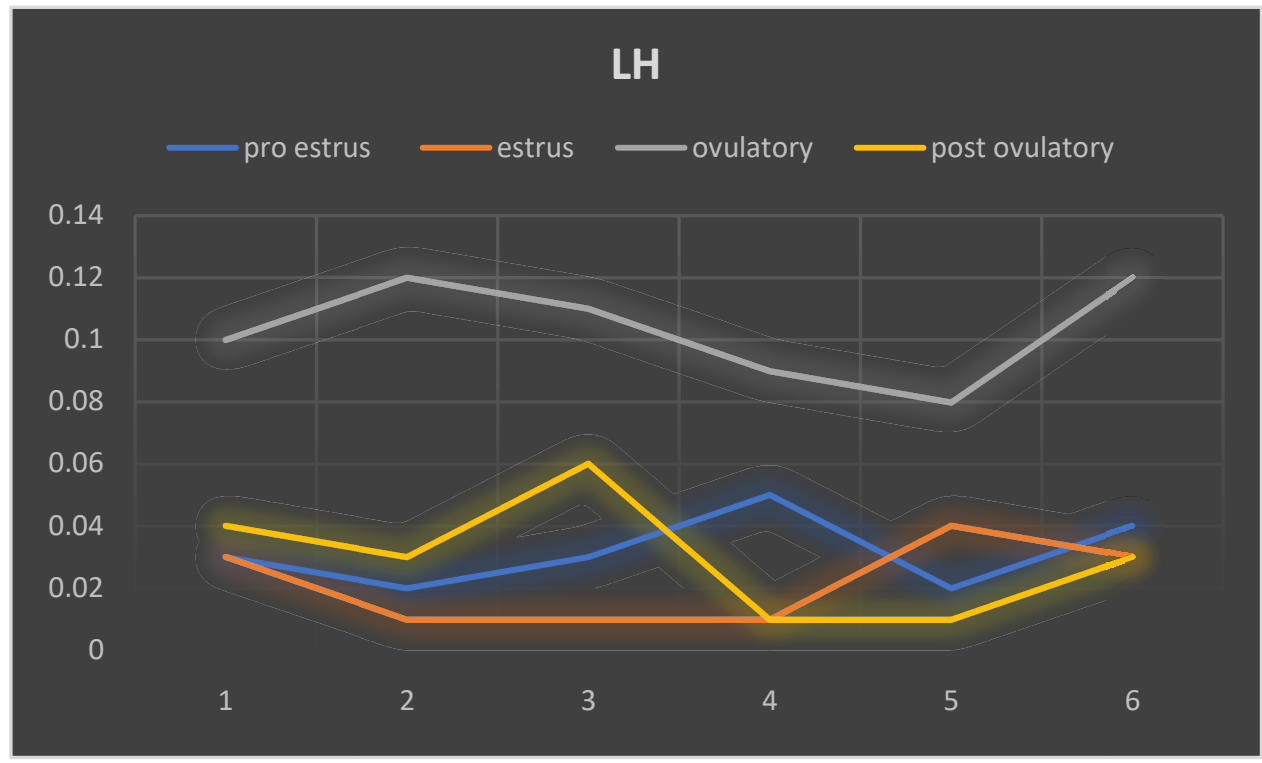

Figure 2: Luteinizing Hormonein the urine sample mIU/ml

Table 3: Estradiolin the urine sample $\mathrm{pg} / \mathrm{mL}$

\begin{tabular}{|c|c|c|c|c|c|c|}
\hline Reproductive phase of does & N1 & N2 & N3 & N4 & N5 & N6 \\
\hline pro estrus & 125.75 & 126.94 & 121.47 & 124.1 & 120.11 & 128.3 \\
\hline estrus & 112.62 & 115.9 & 113.4 & 115.61 & 114.23 & 117.48 \\
\hline ovulatory & 550.3 & 590.6 & 640.1 & 540.31 & 610.41 & 600.7 \\
\hline post ovulatory & 982.46 & 930.41 & 980.13 & 920.1 & 923.12 & 943.21 \\
\hline
\end{tabular}

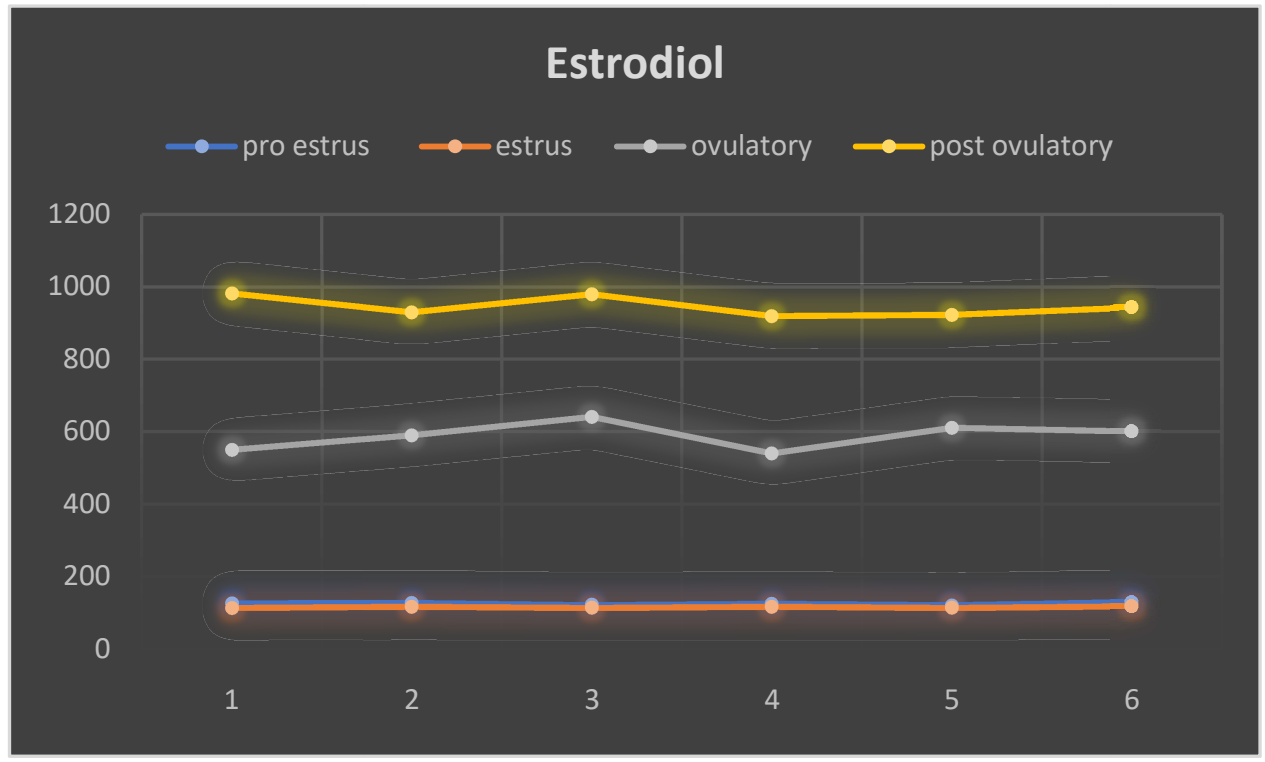

Figure 3: Estradiolin the urine sample $\mathrm{pg} / \mathrm{mL}$

Table 4: Testosterone in the urine sample $\mathrm{ng} / \mathrm{mL}$

\begin{tabular}{|c|c|c|c|c|c|c|}
\hline Reproductive phase of does & N1 & N2 & N3 & N4 & N5 & N6 \\
\hline pro estrus & 0.069 & $\mathbf{0 . 0 7 3}$ & $\mathbf{0 . 0 6 4}$ & $\mathbf{0 . 0 6 5}$ & $\mathbf{0 . 0 7 1}$ & $\mathbf{0 . 0 6 8}$ \\
\hline estrus & $\mathbf{0 . 0 2 7}$ & $\mathbf{0 . 0 2 7}$ & $\mathbf{0 . 0 3 1}$ & $\mathbf{0 . 0 2 8}$ & $\mathbf{0 . 0 2 8}$ & $\mathbf{0 . 0 2 5}$ \\
\hline ovulatory & $\mathbf{0 . 0 3 1}$ & $\mathbf{0 . 0 3 6}$ & $\mathbf{0 . 0 3 4}$ & $\mathbf{0 . 0 2 9}$ & $\mathbf{0 . 0 3 2}$ & $\mathbf{0 . 0 3 3}$ \\
\hline post ovulatory & $\mathbf{0 . 0 4 5}$ & $\mathbf{0 . 0 4 7}$ & $\mathbf{0 . 0 4 1}$ & $\mathbf{0 . 0 5}$ & $\mathbf{0 . 0 5 1}$ & $\mathbf{0 . 0 4 8}$ \\
\hline
\end{tabular}




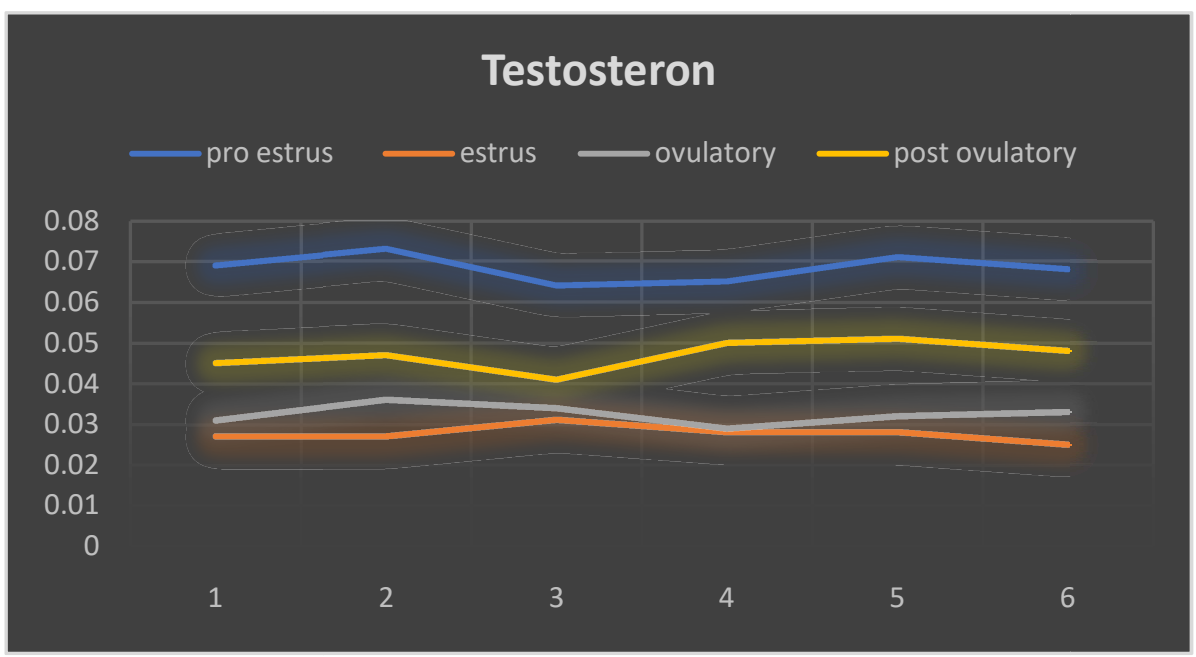

Figure 4: Testosterone in the urine sample $\mathrm{ng} / \mathrm{mL}$

Table 5: Comparison with Proestrus phase group

\begin{tabular}{|c|c|c|c|c|c|c|}
\hline \multicolumn{7}{|c|}{ ANOVA } \\
\hline & & Sum of Squares & df & Mean Square & $\mathbf{F}$ & Sig. \\
\hline \multirow[t]{3}{*}{ estrus } & Between Groups & .001 & 2 & .000 & 2.419 & .237 \\
\hline & Within Groups & .001 & 3 & .000 & & \\
\hline & Total & .001 & 5 & & & \\
\hline \multirow[t]{3}{*}{ ovulatory } & Between Groups & .000 & 2 & .000 & 5.357 & .102 \\
\hline & Within Groups & .000 & 3 & .000 & & \\
\hline & Total & .001 & 5 & & & \\
\hline \multirow{3}{*}{$\begin{array}{c}\text { post } \\
\text { ovulatory }\end{array}$} & Between Groups & .000 & 2 & .000 & .054 & .949 \\
\hline & Within Groups & .000 & 3 & .000 & & \\
\hline & Total & .000 & 5 & & & \\
\hline
\end{tabular}

Table 6: Comparison with Estrus phase group

\begin{tabular}{|c|c|c|c|c|c|c|}
\hline \multicolumn{7}{|c|}{ ANOVA } \\
\hline & & Sum of Squares & df & Mean Square & $\mathbf{F}$ & Sig. \\
\hline \multirow[t]{3}{*}{ pro estrus } & Between Groups & .000 & 3 & .000 & .139 & .928 \\
\hline & Within Groups & .000 & 2 & .000 & & \\
\hline & Total & .000 & 5 & & & \\
\hline \multirow[t]{3}{*}{ ovulatory } & Between Groups & .000 & 3 & .000 & .756 & .613 \\
\hline & Within Groups & .000 & 2 & .000 & & \\
\hline & Total & .001 & 5 & & & \\
\hline \multirow{3}{*}{$\begin{array}{c}\text { post } \\
\text { ovulatory }\end{array}$} & Between Groups & .000 & 3 & .000 & .944 & .551 \\
\hline & Within Groups & .000 & 2 & .000 & & \\
\hline & Total & .000 & 5 & & & \\
\hline
\end{tabular}

Table 7: Comparison with ovulatory phase group

\begin{tabular}{|c|c|c|c|c|c|c|}
\hline \multicolumn{7}{|c|}{ ANOVA } \\
\hline & & Sum of Squares & df & Mean Square & $\mathbf{F}$ & Sig. \\
\hline \multirow[t]{3}{*}{ pro estrus } & Between Groups & .000 & 3 & .000 & 4.167 & .200 \\
\hline & Within Groups & .000 & 2 & .000 & & \\
\hline & Total & .000 & 5 & & & \\
\hline \multirow[t]{3}{*}{ estrus } & Between Groups & .000 & 3 & .000 & .372 & .786 \\
\hline & Within Groups & .001 & 2 & .000 & & \\
\hline & Total & .001 & 5 & & & \\
\hline \multirow{3}{*}{$\begin{array}{c}\text { post } \\
\text { ovulatory }\end{array}$} & Between Groups & .000 & 3 & .000 & 4.167 & .200 \\
\hline & Within Groups & .000 & 2 & .000 & & \\
\hline & Total & .000 & 5 & & & \\
\hline
\end{tabular}




\begin{tabular}{|c|c|c|c|c|c|c|}
\hline \multicolumn{7}{|c|}{ ANOVA } \\
\hline & & Sum of Squares & df & Mean Square & $\mathbf{F}$ & Sig. \\
\hline \multirow[t]{3}{*}{$\begin{array}{c}\text { pro } \\
\text { estrus }\end{array}$} & $\begin{array}{l}\text { Between } \\
\text { Groups }\end{array}$ & .000 & 2 & .000 & .054 & .949 \\
\hline & Within Groups & .000 & 3 & .000 & & \\
\hline & Total & .000 & 5 & & & \\
\hline \multirow[t]{3}{*}{ estrus } & $\begin{array}{l}\text { Between } \\
\text { Groups }\end{array}$ & .001 & 2 & .001 & 6.094 & .088 \\
\hline & Within Groups & .000 & 3 & .000 & & \\
\hline & Total & .001 & 5 & & & \\
\hline \multirow[t]{3}{*}{ ovulatory } & $\begin{array}{l}\text { Between } \\
\text { Groups }\end{array}$ & .000 & 2 & .000 & .214 & .818 \\
\hline & Within Groups & .000 & 3 & .000 & & \\
\hline & Total & .001 & 5 & & & \\
\hline
\end{tabular}

Table 9: Statistics

\begin{tabular}{|c|c|c|c|c|c|}
\hline \multicolumn{6}{|c|}{ Statistics } \\
\hline & & pro estrus & estrus & ovulatory & post ovulatory \\
\hline \multirow{2}{*}{$\mathbf{N}$} & Valid & 6 & 6 & 6 & 6 \\
\hline & Missing & $\mathbf{0}$ & $\mathbf{0}$ & $\mathbf{0}$ & $\mathbf{0}$ \\
\hline \multicolumn{2}{|c|}{ Mean } & .0517 & .0850 & .0433 & .0217 \\
\hline
\end{tabular}

\section{DISCUSSION}

Excretory sources are very often good indicators of the physiological status of animals in a colony. Hence, animals communicate better through the chemical signals that are present in the excretory products. Among the excretory products, the urine excreted by an animal in visually conspicuous sites acts as a good indicator of communication. Furthermore, the volatile organic compounds present in the excretory sources could be used as markers for the identification of the physiological status or diseased conditions [34]. It is possible that the increase in testosterone secretion leads to behavioural changes that improve the success of mating although reproductive behaviour does not appear to be acutely sensitive to testosterone concentrations It appears that this early increase in LH mean concentration, and pulse magnitude and frequency, was necessary to induce testicular growth and spermatogenesis in pubescent goat kids.female goats were choosing males solely on morphological cues, it would have been expected that they would show no preference for either bucks or untreated stags. However, females showed preference for bucks. Once an animal has stopped growing, morphological changes resulting from increasing or decreasing Testosterone concentrations maybe less plastic and morphological changes are minimal [35]. Increased LH concentrations at 6-8 weeks of age in rambucklings is due to an increase in the pituitary sensitivity to GnRH at that age [36]. Since the sensitivity of the hypothalamo-pituitary axis to gonadal steroid inhibitory feedback decreases after puberty [37], an increase in Testosterone concentration is necessary to suppress $\mathrm{LH}$ secretion. This phenomenon makes the male prepubertal goats to grow with 
masculinityIn the majority of seasonal breeders, timing of birth is crucial for offspring survival [38-41] because off spring born early in temperate environments have longer access to high quality food than those born later in the season. Thus, if possible, females should breed early in the breeding season to further aid in improving their reproductive success. To maximize fitness, females need to be able to distinguish between high- and low-quality males throughout the breeding season, as they may not become pregnant after their first estrus cycle.

The quantification of reproductive hormones during the different reproductive phases of goats have already been described but, to the best of our knowledge, the present work is the first to quantify the reproductive hormone in urine throughout the reproductive phase in this species.In this study, peak frequencies of both LH and Testosterone were high during the phase ovulation, low in proestrus phase it may increase at the time of arousal thereafter. The peak magnitude of LH showed a progressive decrease in post ovulation. The peak magnitude of Testosterone, however, increased after 18 weeks of age. This appears to trigger the increased Testosterone concentration which is necessary to suppress the LH secretion after sexual maturity. LH and Testosterone are known to be secreted episodically in adult rams [42] and goats [43].

This pulsatile secretion of $\mathrm{LH}$ and Testosterone was evident prepubertal female, when the study commenced. Pulsatile secretion of LH was observed as early as 7 weeks of age in lambs [44] and 16 weeks of age in kids [45]. It is generally believed that Testosterone is secreted from the Leydig cells under the influence of LH. This study does not provide a conclusive proof for a cause-effect relationship, but the consistent occurrence of Testosterone peaks following $\mathrm{LH}$ peaks implies that such a relationship probably occurs in this species

The present study indicates that the level of reproductive hormones fluctuates according to the neural and endocrinal interaction (feedback). The external ques like olfactory, auditory, optic and tactile may modify secretion of the hormone and neural interplay mechanism in the goat

\section{ACKNOWLEDGEMENT}

We are indebted to the management of Jamal Mohammed college supported to carry out this research; we are grateful to RCL DIAGNOSTIC LAB Bengaluru for supporting us in analysis of samples, we appreciate and acknowledge the research scholars of CHEMICAL ECOLOGY RESEARCH LABORATORY Dept of Environmental Biotechnology Bharathidasan university, we are grateful to $\mathrm{Mr}$. Muruganthe Goat farm owner for 
allowing us to take samples for this research, we are thankful to Bishop Heber college where the first author currently working as assistant professor in the Department Of Zoology for extending their fullest cooperation to fulfill this research. We appreciate the research scholars and students from Veterinary University Training and Research Centre, Tiruchirapalli - 620023

\section{REFERENCE}

[1] Delgadillo J.A, Flores J.A, Veliz F.G, Duarte G, Vielma J, Hernandez H, Fernandez I.G. Importance of the signals provided by the buck for the success of the male effect in goats. Reprod. Nutr. Dev. 2006; 46: 391-400

[2] Rivas-Muñoz R, Fitz-Rodríguez G, Poindron P, Malpaux B, Delgadillo J.A. Stimulation of estrous behavior in grazing female goats by continuous or discontinuous exposure to males. J. Anim. Sci. 2007; 85: 1257-1263.

[3] Iwata E, Wakabayashi Y, Kakuma Y, Kikusui T, Takeuchi Y, Mori Y. Testosterone-dependent primer pheromone production in the sebaceous gland of male goat. Biol. Reprod. 2000; 62: 806-810.

[4] Sugiyama T, Sasada H, Masaki J, Yamashita K. Unusal fatty acids with specific odour from mature male goat. Agri. Biol. Chem. 1981; 45: 2655-2658.

[5] Chemineau P. Possibilities for using bucks to stimulate ovarian and oestrous cycles in anovulatory goats-A review. Livest. Prod. Sci. 1987; 17:135-147.

[6] Knight T.W, Lynch P.R. Source of ram pheromones that stimulate ovulation in the ewe. Anim. Reprod. Sci. 1980; 3: 133-136.

[7] Knight T.W, Peterson A.J, Payne E. The ovarian and hormonal response of the ewe to stimulation by the ram early in the breeding season. Theriogenology. 1978; 10: 343353.

[8] Ungerfeld R, Silva L. The presence of normal vaginal flora is necessary for normal sexual attractiveness of estrous ewes. Appl. Behav. Sci. 2004; 93: 245-250.

[9] Shelton M. Reproduction and breeding of goats. J. Dairy Sci. 1978; 61: 994-1010.

[10] Underwood E.J, Shier F.L, Davenport N. Studies in sheep husbandry. The breeding season in Merino crossbreeds and British breeds ewes in the agricultural districts. J. Agri. 1944; 11:135143.

[11] Iwata E, Kikusui T, Takeuchi Y, Mori Y. Substances derived from 
4-ethyl octanoic acid account for primer pheromone activity for the male effect in goats. J. Vet. Med. Sci. 2003; 65: 1019-1021.

[12] Sasada H, Sugiyama T, Yamashita K, Masaki J. Identification of specific odor components in mature male goat during the breeding season. Jpn. J. Zootech. Sci. 1983; 54: 401-408.

[13] Tilbrook A.J, Cameron A.W.N. Ram mating preferences for wooly rather than recently shorn ewes. Appl. Anim. Behav. Sci. 1989; 24: 301-312.

[14] Ungerfeld R, Silva L. The presence of normal vaginal flora is necessary for normal sexual attractiveness of estrous ewes. Appl. Behav. Sci. 2004; 93: 245250.

[15] Cohen-Tannoudji J, Einhorn J, Signoret J.P. Ram sexual pheromone: First approach of chemical identification. Physiol. Behav. 1994; 56: 955-961.

[16] Bouissou M.F. Effet de l'ablation des bulbesolfactifs sur la reconnaissance du jeune au samère chez les ovins. Rev. Comp. Anim. 1968; 3: 77-83.

[17] Kendrick K.M, Lévy F, Keverne E.B. Changes in the sensory processing of olfactory signals induced by birth in sheep. Science. 1992; 8: 833-836.

[18] Nowak R, Keller M, Levy S. Mother-young relationship in sheep: A model for a multidisciplinary approach of the study of attachment in mammals. J. Neuroendocrinol. 2011; 23: 1042-1053.

[19] Keller M, Meurisse M, Lévy F. Mapping of brain networks involved in consolidation of lamb recognition memory. Neuroscience. 2005; 133: 359-369.

[20] Porter R.H, Levy F, Poindron P, Litterio M, Schaal B, Beyer C. Individual olfactory signatures as major determinants of early maternal discrimination in sheep. Dev. Psychobiol. 1991; 24: 151158

[21] Kendrick K.M, Lévy F, Keverne E.B. Changes in the sensory processing of olfactory signals induced by birth in sheep. Science. 1992; 8: 833-836.

[22] Keverne E.B, Lévy F, GuevaraGuzman R, Kendrick K.M. Influence of birth and maternal experience on olfactory bulb neuro transmitter release. Neuroscience. 1993; 56: 557-565.

[23] Nowak R, Keller M, Levy S. Mother-young relationship in 
sheep: A model for a multidisciplinary approach of the study of attachment in mammals.

J. Neuroendocrinol. 2011; 23: 1042-1053.

[24] Poindron P, Levy F, Krehbiel D. Genital, olfactory and endocrine interactions in the development of maternal behavior in the parturient ewe. Psychoneuroendocrinology. 1988; 13: 99-125.

[25] Porter R.H, Levy F, Poindron P, Litterio M, Schaal B, Beyer C. Individual olfactory signatures as major determinants of early maternal discrimination in sheep. Dev. Psychobiol. 1991; 24: 151158.

[26] Alexander G, Stevens D. Odour cues to maternal recognition of lambs: An investigation of some possible sources. Appl. Anim. Ethol. 1982; 10: 165-175.

[27] Alexander G, Stevens D, Bradley L.R. Washing lambs and confinement as aids to fostering. Appl. Anim. Ethol. 1983; 10: 251-261.

[28] Bean N.J. Olfactory and vomeronasal mediation of ultrasonic vocalizations in male mice. Physiol. Behav. 1982; 8228: 31-37.

[29] Nowak R, Murphy T.M, Lindsay D.R, Alster P, Anderson R, Berk
K. Development of a preferential relationship with the mother by the newborn lamb: Importance of the suckling actiity. Physiol. Behav. 1997; 62: 681-688.

[30] Nowak R, Murphy T.M, Lindsay D.R, Alster P, Anderson R, Berk K. Development of a preferential relationship with the mother by the newborn lamb: Importance of the suckling actiity. Physiol. Behav. 1997; 62: 681-688.

[31] Knight T.W, Lynch P.R. Source of ram pheromones that stimulate ovulation in the ewe. Anim. Reprod. Sci. 1980; 3: 133-136.

[32] Walkden-Brown SW, Restall BJ and Henniawati (1993c) The male effect in Australian cashmere goats 1. Ovarian and behavioural response of seasonally anovulatory does following the introduction of bucks Animal Reproduction Science 32 41-53

[33] Martin GB, Oldham CM, Cognie $Y$ and Pearce DT (1986) The physiological responses of anovulatory ewes to the introduction of rams - a review Livestock Production Science. 15: 219-247

[34] Sethi, A., Kovaleva, E., Slack, J. M., Brown, S., Buchman, G. W, and Scharf, M. E. (2013a). A 
GHF7 cellulase from the protist symbiont community of Reticulitermes flavipes enables more efficient lignocellulose processing by host enzymes. Archives Insect Biochem. Physiol. 84, 175-193. doi: 10.1002/ arch. 21135

[35] Ball, J., 1940. The effect of testosterone on the sex behavior of female rats. J. Comp. Psychol. 29, 151-165.

[36] Lee, V.W.K., Cumming, I.A., de Kretser, D.M., Findlay, J.K., Hudson, B. and Keogh, E.J., 1976. Regulation of gonadotrophin secretion in rams from birth to sexual maturity. II. Response of the pituitary-testicular axis to LHRH infusion. I. Reprod. Fertil., 46: 7-1 1.

[37] Olster, D.H. and Foster, D.L., 1986. Control of gonadotrophin secretion in the male during puberty: A decrease in response to steroid inhibitory feed back in the absence of an increase in steroidindependent drive in the sheep. Endocrinology, 118: 2225-2234

[38] Clutton-Brock, T.H., Major, M., Albon, S.D., Guinness, F.E., 1987. Early development and population dynamics in red deer, I. Density- dependent effects on juvenile survival. J. Anim. Ecol. 56, 53-67.

[39] Côté, S.D., Festa-Bianchet, M., 2001. Birthdate, mass and survival in mountain goat kids: effects of maternal characteristics and forage quality. Oecologia 127, 230-238.

[40] Fairbanks, W.S., 1993. Birthdate, birthweight, and survival in pronghorn fawns. J.Mammal. 74, 129-135

[41] Green, W.C.H., Rothstein, A., 2009. Persistent influences of birth date on dominance, growth and reproductive success in bison. J. Zool. 230, 177-186.

[42] Pelletier, J., Gamier, D.H., de Reviers, M.M., Terqui, M. and Ortavant, R., 1982. Seasonal variation in $\mathrm{LH}$ and testosterone release in rams of two breeds. J. Reprod. Fertil., 64: 341-346.

[43] Muduuli, D.S., Sanford, L.M., Palmer, W.M. and Howhmd, B.E., 1979. Secretary patterns and circadian and seasonal changes in luteinizing hormone, follicle stimulating hormone, prolactin and testosterone in the male Pygmy goat. J. Anim. Sci., 49: 543-553.

[44] Olster, D.H. and Foster, D.L., 1986. Control of gonadotrophin secretion in the male during puberty: A decrease in response to 
steroid inhibitory feed back in the absence of an increase in steroidindependent drive in the sheep. Endocrinology, 118: 2225-2234.

[45] Chakraborty, P.K., Stuart, L.D. and Brown, J.L., 1989. Puberty in the male Nubian goat: Serum concentrations of $\mathrm{LH}, \mathrm{FSH}$ and testosterone from birth through puberty and semen characteristics at sexual maturity. Anim. Reprod. Sci., 20: 91-101. 